Proceedings of SALT 31: 82-103, 2021

\title{
Intervention effects follow from scope rigidity in Turkish*
}

\author{
Ömer Demirok \\ Boğaziçi University
}

\begin{abstract}
Intervention effects in Turkish wh-questions can be obviated by the overt movement of the wh-phrase past the intervener. This cross-linguistically robust method of intervention obviation raises an important question: what is it that bans the covert movement of the wh-phrase? I argue that this question finds a natural answer in Scope Rigidity, a general restriction on the availability of inverse scope. Importantly, including wh-phrases in the domain of Scope Rigidity calls for a scopal account of wh-phrases. I argue that this general approach has welcome consequences in explaining the source of intervention effects and in predicting what can intervene, and can even accommodate how extraction islands containing wh-phrases behave in intervention configurations.
\end{abstract}

Keywords: Turkish, wh-questions, intervention effects, scope rigidity, islands

\section{Introduction}

Descriptively, intervention effects in wh-questions (also called Beck effects) are ordering restrictions between wh-phrases and a certain class of elements called interveners (Hoji 1985; Beck 1996; Beck \& Kim 1997; Pesetsky 2000; Tanaka 2003; Beck 2006; Mayr 2014; Branan 2018; Kotek 2019a: a.o.). ${ }^{1}$ This paper aims to understand the nature of intervention effects in wh-questions, focusing on Turkish. Intervention effects in Turkish were reported in Beck \& Kim 1997 and Kelepir 2001, and verified through a more comprehensive survey in Kesen 2010.

A typical paradigm for demonstrating intervention effects is provided in (1). As shown in (1a), Turkish normally allows wh-in-situ. However, speakers reject a whquestion where an object wh-phrase occurs in-situ and is preceded by an intervener, in this case the negative concord item hiçkimse 'anybody', as shown in (1b). The intervention effect in (1b) can be eliminated by overtly scrambling the wh-phrase

* This paper is partly based on a brief discussion that appears in my dissertation, Demirok 2019: Ch7. I owe my thanks to all the people that I acknowledge in my dissertation. In addition, I thank the audiences at SALT31, and TU+6 where an earlier version of this paper was presented. Finally, I am grateful to my Turkish consultants for their patience and help. All errors are solely my own.

1 In the literature, the label 'intervention effect' has also been used to describe various phenomena different from the one discussed in this paper. See Mayr 2020 for a comprehensive review. 
Intervention effects follow from scope rigidity in Turkish

to the left of the intervener as in (1c). Note that the paradigm presented here is well-documented and is in no way unique to Turkish. For example, fully parallel data in Korean can be found in Beck \& Kim 1997.
a. Partide Pelin
kim-le
konuş-ma-d1?
party-LOC Pelin
who-with
talk-NEG-PAST
'Who ${ }_{1}$ is such that Pelin did not to talk to them 1 at the party?'
b. *Partide hiçkimse kim-le konuş-ma-d1? party-LOC anybody ${ }_{\mathrm{NCI}}$ who-with talk-NEG-PAST Intended: 'Who ${ }_{1}$ is such that nobody talked to them ${ }_{1}$ at the party?'
c. Partide kim-le hiçkimse konuş-ma-dı? party-LOC who-with anybody ${ }_{\mathrm{NCI}}$ talk-NEG-PAST 'Who 1 is such that nobody talked to them ${ }_{1}$ at the party?'2

Given that only one of the strings in (1b) and (1c) has the target interpretation, it may seem like intervention is a purely linear constraint that prevents interveners like hiçkimse from preceding wh-phases. But this initial hypothesis is easily falsified. Intervention is more accurately characterized as the inability of a wh-phrase to scope over a c-commanding intervener (Mayr 2020). As shown in (2), an intervener in the matrix clause has no problem preceding/c-commanding a wh-phrase that scopes inside an embedded clause (forming an embedded wh-question). Similarly, an intervener that precedes but does not c-command a wh-phrase causes no intervention, as shown in (3).

(2) Hiçkimse [parti-de kim-le konuştuğumu ] bil-m-iyor. anybody $_{\mathrm{NCI}}$ party-LOC who-with talk.NMLZ.1SG know-NEG-IMPF 'Nobody knows who I talked to at the party.'

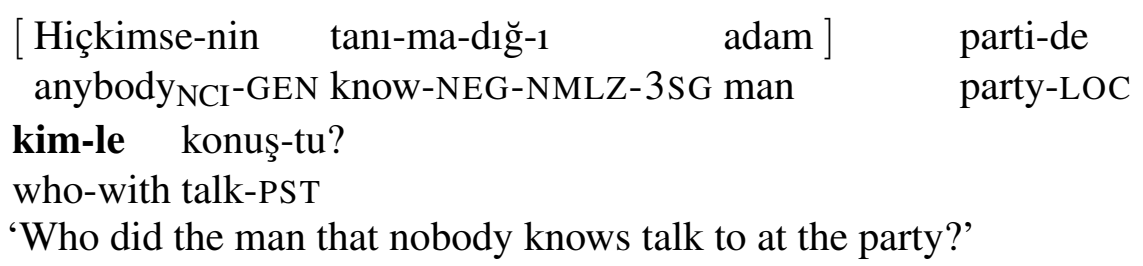

One of the most difficult tasks in building a theory of intervention effects is predicting which class of elements cause intervention in a given language, as the cross-linguistic picture does not seem to be uniform (Beck 2006). Hence, detailed investigations of intervention effects in individual languages are needed. In a way that addresses this need, an exciting empirical generalization for Japanese has recently been proposed in Erlewine \& Kotek 2017a,b and Kotek 2019a. Erlewine and Kotek argue that only scope rigid expressions cause intervention effects in Japanese wh-

2 I use singular they/them throughout the paper. 
questions, where scope rigid = cannot reconstruct under negation. In other words, if an expression that cannot reconstruct under negation c-commands a wh-phrase at LF, we get uninterpretability. To illustrate, the syntactic placement of dake 'only' is argued to not only determine whether the expression it creates is scope rigid or not but also determine whether that expression causes intervention in wh-questions or not. Under the presumed definition of scope rigidity, dake 'only' attaching outside a $\mathrm{P}$ head like to 'with' creates a scope rigid expression, as shown in (4a), whereas dake 'only' attaching inside the same $\mathrm{P}$ head does not create a scope rigid expression, as shown in (4b). The crucial contrast in (5) is that the scope rigid expression, i.e. NP-to-dake, causes intervention but its non scope rigid variant, i.e. NP-dake-to, does not.

$$
\begin{aligned}
& \text { a. Taro-wa Hanako-to-dake hanasa-nak-atta. } \\
& \text { Taro-TOP Hanako-with-only talk-NEG-PST } \\
& \text { Lit: 'Taro didn't talk only with Hanako.' (only }>\neg, * \neg>\text { only) } \\
& \text { b. Taro-wa Hanako-dake-to hanasa-nak-atta. } \\
& \text { Taro-TOP Hanako-only-with talk-NEG-PST } \\
& \text { Lit: 'Taro didn't talk with only Hanako.' (only }>\neg, \neg>\text { only) } \\
& \text { a. *Taro-wa Hanako-to-dake nani-o tabe-ta-no? } \\
& \text { Taro-TOP Hanako-with-only what-ACC eat-PST-Q } \\
& \text { Intended: 'What did Taro eat (only) with (only) Hanako?' } \\
& \text { b. Taro-wa Hanako-dake-to nani-o tabe-ta-no? } \\
& \text { Taro-TOP Hanako-only-with what-ACC eat-PST-Q } \\
& \text { 'What did Taro eat (only) with (only) Hanako?' }
\end{aligned}
$$

Japanese: (Erlewine \& Kotek 2017a)

In essence, Erlewine and Kotek's insight is that scope rigidity is a key notion in successfully predicting intervention effects in wh-questions. In this paper, I build on this general insight and argue that intervention effects can be made to follow from scope rigidity in Turkish, as well. However, my proposal will substantially diverge from Erlewine and Kotek's in two ways.

First, Erlewine and Kotek take scope rigidity to be an idiosyncratic property of scope-takers, diagnosed by the impossibility of reconstruction under negation. While I do not take issue with the way they diagnose scope rigidity for Japanese, I will take scope rigidity to be a general constraint active in the grammar of Turkish that effectively bans inverse scope. To highlight this difference, hereafter, I will refer to the general constraint as Scope Rigidity (i.e. initials in capitals).

Second, Erlewine and Kotek's explanation of intervention effects in Japanese, articulated in most detail in Kotek 2019a, makes the assumption that wh-phrases are interpreted in-situ by pointwise composition. As will be discussed, this assumption 
is crucial for them to be able to state the source of the intervention effect. Following recent proposals that can derive island-insensitive wh-in-situ by cyclic scope-taking (Charlow 2014, 2020; Demirok 2019), I reject the necessity of pointwise composition, and instead argue that wh-phrases, too, are scope-takers and hence are kinds of objects subject to Scope Rigidity, understood as a general constraint of a given grammar. Finally, as a consequence of the scopal account that I will adopt for wh-phrases, what exactly goes wrong in an intervention configuration will be different from the one in Kotek 2019a.

In essence, I argue that intervention in wh-questions is a direct consequence of Scope Rigidity in Turkish, i.e. inverse scope not being available for wh-phrases. In a sentence like (6), the inability of $\mathrm{QP}_{2}$ to scope above $\mathrm{QP}_{1}$ results in the lack of ambiguity (Kelepir 2001; Özyıldız 2017). However, in a so-called intervention configuration such as the one in (7), the inability of $\mathrm{QP}_{2}$ to scope above $\mathrm{QP}_{1}$ has a fatal consequence, for there is no interpretable logical form in which the wh-phrase scopes below a negative concord item which needs to scope below negation.

$$
\begin{aligned}
& {\left[\mathrm{QP}_{1} \mathrm{Bi} \text { çocuk }\right]\left[\mathrm{QP}_{2} \text { her elmay1 }\right] \text { ye-di. }} \\
& \text { a child every apple.ACC eat-PST } \\
& =\exists \mathrm{x} \text { child }(\mathrm{x}) \& \forall \mathrm{y} \text { apple }(\mathrm{y}) \rightarrow \operatorname{ate}(\mathrm{y})(\mathrm{x}) \Leftarrow \text { SURFACE SCOPE } \\
& \neq \forall \mathrm{y} \text { apple }(\mathrm{y}) \rightarrow \exists \mathrm{x} \text { child }(\mathrm{x}) \& \text { ate }(\mathrm{y})(\mathrm{x}) \Leftarrow \text { INVERSE SCOPE }
\end{aligned}
$$

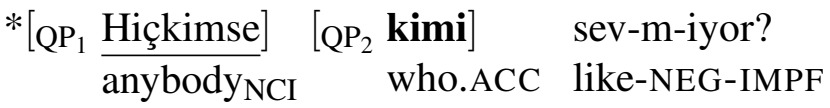

$$
\begin{aligned}
& =(\text { no interpretation is derived }) \quad \Leftarrow \text { SURFACE } \\
& \neq \lambda \text { p. } \exists \mathrm{x}: \operatorname{human}(\mathrm{x}) \&\left[\mathrm{p}=\lambda \mathrm{w} . \neg \exists \mathrm{y}: \operatorname{human}(\mathrm{y}) \& \operatorname{like}_{\mathrm{w}}(\mathrm{x})(\mathrm{y})\right] \Leftarrow \operatorname{INVERSE}
\end{aligned}
$$

The paper is structured as follows. In Section 2, I briefly discuss the proposal in Kotek 2019a. In Section 3, I substantiate my proposal that intervention effects follow from Scope Rigidity if wh-phrases are scope-takers. Section 4 discusses additional predictions that are made under the proposed theory. Section 5 concludes the paper, pointing to some loose ends.

\section{Kotek (2019a): $\lambda$-abstraction over alternatives causes intervention}

Intervention effects in wh-questions concern in-situ wh-phrases. Since wh-in-situ is typically island-insensitive, prominent semantic theories of intervention have related intervention effects to the special way grammars may be generating islandinsensitivity. For example, a widely known explanation of intervention effects proposed in Beck 2006, implemented in different forms in Cable 2010 and Kotek $2019 \mathrm{~b}$, rests on the assumption that wh-phrases compose in-situ and are not scope- 
taking elements. ${ }^{3}$

Under this idea that wh-phrases can be interpreted in-situ, Erlewine \& Kotek (2017a,b) explore a novel semantic account of intervention effects, articulated in most detail in Kotek 2019a. What goes wrong in an intervention configuration, resulting in uninterpretability, is argued to be the well-known technical problem in defining $\lambda$-abstraction along with pointwise composition (Rooth 1985; Hagstrom 1998; Kratzer \& Shimoyama 2002; Shan 2004). In a nutshell, the problem is that in a configuration like the one in (8), if $\llbracket \alpha \rrbracket$ denotes a non-singleton set of alternatives, we are unable to define a $\lambda$-abstraction rule that derives the correct set of functions for the meaning of $\llbracket \beta \rrbracket$. $^{4}$

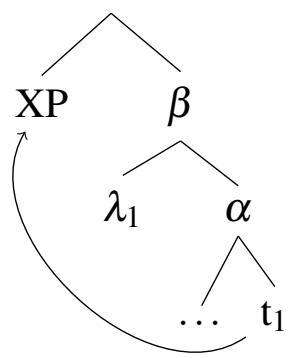

For Erlewine $\&$ Kotek (2017a,b) and Kotek (2019a), $\lambda$-abstraction over alternatives is what causes intervention effects, i.e. uninterpretability. The main empirical finding that is taken to support this claim is that if an expression is scope rigid (as diagnosed by its inability to reconstruct under negation), it causes intervention in wh-questions. To accommodate this finding under the proposed account of intervention effects, they assume, following Shibata (2015), that all argument DPs vacate the vP in Japanese, hence forming a movement chain that triggers $\lambda$-abstraction (Heim $\&$ Kratzer 1998). If an expression happens to be scope rigid, it cannot reconstruct to its base position in the vP, hence the $\lambda$-binder associated with it is part of the logical form. However, if an expression is not scope rigid, it can reconstruct to its base position in the vP, which is assumed to mean that the $\lambda$-binder associated with it is not part of the logical form. Accordingly, intervention arises if $\llbracket \alpha \rrbracket$ in (8) denotes a non-singleton set of alternatives and the moved XP is scope rigid.

Let us illustrate the logic of this theory on the ungrammatical Turkish sentence in (9a), which will have a logical form as in (9b) under the assumptions in Kotek 2019a.

3 Beck's assumption is that wh-phrases only have focus semantic values but lack normal semantic values (i.e. their normal semantic values are undefined). Accordingly, under Beck's theory and its later implementations, the intervention effect (i.e. undefinedness) is predicted to occur when a wh-phrase remains in the immediate scope of an operator that requires the normal semantic value of its prejacent. Due to space reasons, I will not comment on the viability of this approach for Turkish.

4 See Novel \& Romero 2010 for a solution to this problem and Charlow 2014 for a criticism. Essentially, Kotek (2019a) argues that we should not try to fix the problem. 
Intervention effects follow from scope rigidity in Turkish

Here, we need the node labelled $\beta$ to denote a set of functions from individuals to propositions, i.e. $\{\lambda \mathrm{y} . \lambda \mathrm{w}$. y talked to $\mathrm{x}$ in $\mathrm{w} \mid \operatorname{human}(\mathrm{x})\}$, but it instead ends up denoting a function into proposition sets, i.e. $\lambda \mathrm{y}$. $\{\lambda \mathrm{w}$. $\mathrm{y}$ talked to $\mathrm{x}$ in $\mathrm{w}$ human $(\mathrm{x})\}$, which sadece Pelin cannot pointwise combine with. ${ }^{5}$

a. *Sadece Pelin kim-le konuş-tu?

only Pelin who-with talk-PST

Intended: 'Who ${ }_{1}$ is such that it was only Pelin who talked to them ${ }_{1}$ ?'

b.

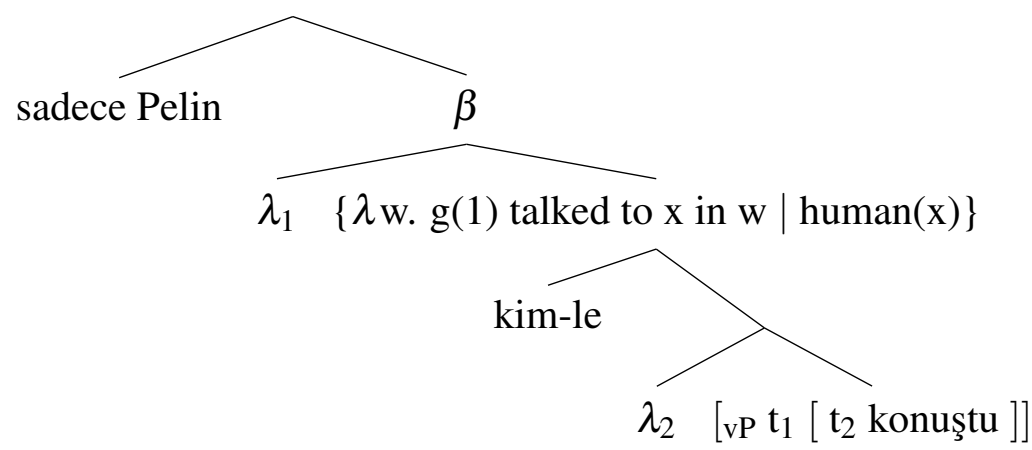

In essence, the semantic uninterpretability here, argued to be the source of the intervention effect, stems from the $\lambda$-abstraction that needs to be interpreted in the path of the alternative computation triggered by the wh-phrase. This is where scope rigidity comes into picture. Unless an expression that has moved across a wh-phrase can reconstruct back into its a position below the wh-phrase, the $\lambda$-binder associated with it will cause uninterpretability, identified as the intervention effect.

All things being equal, this novel approach to intervention predicts intervention in more places than what has been reported in the literature. See Kotek 2019a for a comprehensive discussion of these predictions, which I cannot address here. It should, however, be noted that this proposal cannot be maintained in its most general form. As Kotek points out, not all 'kinds' of $\lambda$-abstraction trigger intervention across alternatives. For example, relativization, even though it involves $\lambda$-abstraction under standard assumptions (Heim \& Kratzer 1998), does not cause intervention. As shown in the simplified logical form for the DP in the Turkish wh-question in (10), the intervention configuration is present but without any intervention effect. ${ }^{6}$

5 Suppose that sadece Pelin denotes the function: $\lambda \mathrm{P} . \lambda \mathrm{w} .\{$ Pelin $\}=\{\mathrm{x}: \mathrm{P}(\mathrm{x})(\mathrm{w})=1\}$. Note that this function would be able to pointwise apply to each member of the correct (but underivable) set of functions, i.e. $\{\lambda \mathrm{y} . \lambda \mathrm{w}$. $\mathrm{y}$ talked to $\mathrm{x}$ in $\mathrm{w} \mid \operatorname{human}(\mathrm{x})\}$.

6 A similar objection can be raised for variable binding, and for theories of de re that require binding (Percus 2000). 
a. [DP Pelin'in kim-e yolla-dı $\breve{g}-1 \quad$ hediye ] pahalı-ydı?

Pelin-GEN who-DAT send-NMLZ-3SG gift expensive-PST

'Who ${ }_{1}$ is such that the gift Pelin sent to them ${ }_{1}$ was expensive?'

b.

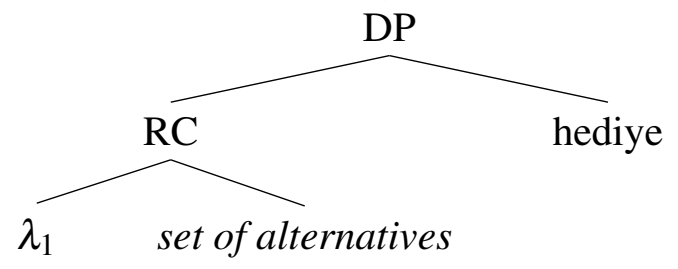

Pelin'in kime $\mathrm{t}_{1}$ yolladığ

Furthermore, this explanation of intervention effects relies on an idiosyncratic definition of scope rigidity (i.e. inability to reconstruct under negation) for Japanese. It is not clear to what extent this definition may be useful in predicting intervention effects in other languages. For example, in Turkish, DPs marked by sadece 'only' are not scope rigid under this idiosyncratic definition. As shown in, the string in (11) allows two readings (only distinguished by prosody). However, sadece-phrases do cause intervention in Turkish, as was shown in (9a), which could only be predicted under Kotek's theory if sadece-phrases are scope rigid. Hence, it seems that the idiosyncratic definition of scope rigidity that makes correct predictions for Japanese may not directly extend to languages like Turkish that are typologically quite similar to Japanese.

Toplant1-da sadece Kerim konuş-ma-d1. meeting-LOC only Kerim speak-NEG-PST

(i) 'In the meeting, it was only Kerim who didn't speak.'

(ii) 'In the meeting, it wasn't only Kerim who spoke.'

Nevertheless, the empirical findings that Erlewine and Kotek report for Japanese are impressive and do indeed suggest scope rigidity plays a key role in predicting intervention effects in Japanese. Building on their insight to link intervention effects to scope rigidity, I propose an alternative account of intervention effects under a scopal account of wh-phrases, focusing on Turkish.

\section{Intervention effects under a scopal theory of wh-phrases}

I propose a theory of the intervention effects in Turkish that rests on two assumptions. First, I assume that wh-phrases are scope-takers like generalized quantifiers. Second, I assume that Scope Rigidity is a general constraint active in the grammar of Turkish. Combining these two ideas, intervention becomes a direct consequence of whphrases being subject to Scope Rigidity. In the next two subsections, I elaborate on 
Intervention effects follow from scope rigidity in Turkish

these two assumptions. In the third subsection, I demonstrate how the combination of these two assumptions explains intervention effects in Turkish.

\subsection{A scopal account of wh-phrases}

I reject the idea that wh-phrases denote alternatives and compose in-situ by pointwise composition (Hamblin 1973; Shimoyama 2006; Cable 2010; Kotek 2019b: a.o.). Instead, I take wh-phrases to be scope-takers akin to generalized quantifiers, an idea that dates back to Karttunen 1977. Although there are alternative implementations of this general idea (Fox 2012; Dayal 2016; Heim 2018; Demirok 2019), for explicitness, I follow the composition articulated in Heim 2000 (also Elliott 2015) where wh-phrases are quantifiers that combine with functions from individuals to proposition sets, as shown in (13b). What builds a proposition set is not the wh-phrase but a Q morpheme (i.e. the propositional variant of the IDENT type shifter (Partee 1986)), defined in (13a). Being scope-takers, wh-phrases need to take scope by moving above the $\mathrm{Q}$ head and existentially quantify into the proposition set that it builds, as illustrated in the logical form in (12b).

a. Kim git-ti?

who leave-PST

'Who left?'

b. $\quad \lambda$ p. $\exists x: \operatorname{human}(x)=1 \& \mathrm{p}=\lambda \mathrm{w}^{\prime} . \mathrm{x}$ left in $\mathrm{w}^{\prime}$

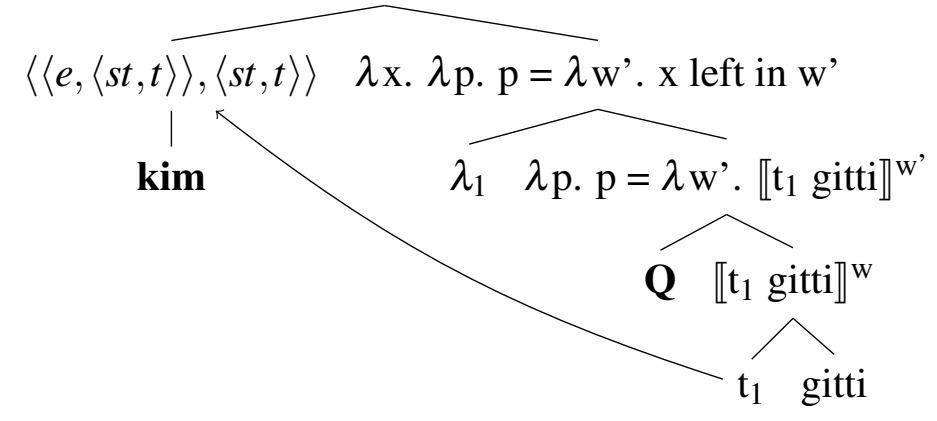

a. $\quad \llbracket \mathrm{Q} \rrbracket^{\mathrm{w}}=\lambda \mathrm{q}_{\langle s, t\rangle} \cdot \lambda \mathrm{p}_{\langle s, t\rangle} \cdot \mathrm{p}=\mathrm{q}$

b. $\quad \llbracket \operatorname{kim} \rrbracket^{\mathrm{w}}=\lambda \mathrm{R}_{\langle e,\langle s t, t\rangle\rangle} \cdot \lambda \mathrm{p} . \exists \mathrm{x}: \operatorname{human}(\mathrm{x})=1 \& \mathrm{R}(\mathrm{x})(\mathrm{p})=1$

An immediate objection to this method of composing wh-questions is that it involves wh-movement, and is not suitable for island-insensitive wh-in-situ. However, recent work has shown that cyclic scope-taking by pied-piping can derive island-violating scope (Charlow 2014, 2020; Elliott 2015; Elliott \& Sauerland 2019; Demirok 2019; Elliott 2021). Assuming that these theories are right, we need not commit to a view of grammar that has a special way of interpreting in-situ wh-phrases such as pointwise composition (Shimoyama 2006) or choice functions (Reinhart 
1998). In fact, a scopal account of wh-phrases may have an advantage. As I will argue in section 3.3, the mysterious ban on covert scrambling of wh-phrases (in languages like Japanese, Turkish, and Korean) can be explained if wh-phrases are expressions that are subject to Scope Rigidity, i.e. scope-takers.

\subsection{Scope Rigidity}

I assume that Scope Rigidity, however it may be formalized, describes the constraint that demands that the relative semantic scope of any two scope-takers be recovered from their relative linear order, as diagrammed in (14). ${ }^{7}$

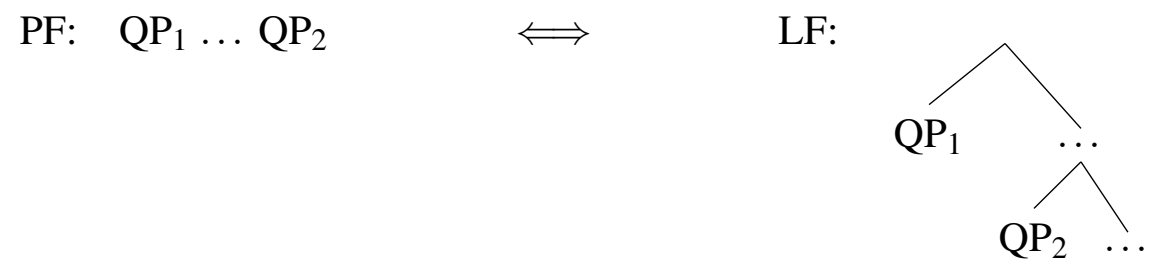

Formalizing Scope Rigidity is beyond the scope of this short contribution. What is important for our purposes is that there is something that prevents scope ambiguities in sentences such as (15) in Turkish. Hence, abstracting away from how best Scope Rigidity can be modelled in the grammar, I will attribute inverse scope being systematically unavailable in Turkish to a general constraint, and call it Scope Rigidity (Kelepir 2001; Öztürk 2005; Özy1ldız 2017). ${ }^{8}$

$$
\begin{aligned}
& {\left[\mathrm{QP}_{1} \mathrm{Bi} \text { çocuk }\right]\left[\mathrm{QP}_{2} \text { her elmay1 }\right] \text { ye-di. }} \\
& \text { a child every apple.ACC eat-PST } \\
& =\exists \mathrm{x} \text { child }(\mathrm{x}) \& \forall \mathrm{y} \text { apple }(\mathrm{y}) \rightarrow \operatorname{ate}(\mathrm{y})(\mathrm{x}) \Leftarrow \text { SURFACE SCOPE } \\
& \neq \forall \mathrm{y} \text { apple }(\mathrm{y}) \rightarrow \exists \mathrm{x} \text { child }(\mathrm{x}) \& \text { ate }(\mathrm{y})(\mathrm{x}) \Leftarrow \text { INVERSE SCOPE }
\end{aligned}
$$

Referring to the data in (16), Özy1ld1z (2017: 929) writes: "linear order determines the relative scope of two quantifier phrases, regardless of what specific type of arguments the quantifier phrases are.". Notably, in (16b) the object quantifier precedes the subject quantifier, suggesting it is part of a movement chain. However, inverse scope is still unavailable, which implies that scope reconstruction is impossible, owing to Scope Rigidity.

7 I take negation and modal markers, which are suffixes on the verb in Turkish, to be outside the domain of this characterization. See Amiraz (this volume) for a different approach on this issue.

8 For example, under the copy theory of movement (Chomsky 1993), Scope Rigidity can be modelled as conditions on the PF and LF interfaces. Notice that Scope Rigidity, in essence, describes the simultaneity of the pronounce the highest copy instruction to the PF interface and the interpret the highest copy instruction to the LF interface, modulo these instructions being restricted to movement chains involving scope-takers. See Bobaljik \& Wurmbrand 2012 for a different approach. 
Intervention effects follow from scope rigidity in Turkish

a. $\quad\left[\mathrm{QP}_{1}\right.$ Çoğu editör $]\left[\mathrm{QP}_{2}\right.$ her kitab-1 $]$ oku-du. most editor every book-ACC read-PST.3S

$\checkmark$ 'Most of the editors were such that they read every book.'

$\boldsymbol{x}$ 'Every book was such that it was read by most of the editors.'

b. $\left[\mathrm{QP}_{2}\right.$ Çoğu kitab-1 $] \quad\left[\mathrm{QP}_{1}\right.$ her editör $] \mathrm{t}_{\mathrm{QP}_{2}}$ oku-du. most book-ACC every editor read-PST.3S

$\checkmark$ 'Most of the books are such that they were read by every editor.'

$\boldsymbol{x}$ 'Every editor is such that s/he read most of the books.'

In the next subsection, I demonstrate how a scopal account of wh-phrases predicts intervention effects under Scope Rigidity.

\subsection{How does Scope Rigidity predict intervention effects?}

Under an in-situ semantics for wh-phrases, explaining the contrast (17a) and (17b) requires the stipulation that covert wh-scrambling is not permitted. If covert whscrambling were possible in Turkish, we would observe intervention obviation by the covert analogue of the overt wh-scrambling which does eliminate the intervention effect in (17b).

$$
\begin{aligned}
& \text { a. * }\left[\mathrm{QP}_{1} \text { Hiçkimse }\right] \quad\left[\mathrm{QP}_{2} \text { kim-le }\right] \text { konuş-ma-d1? } \\
& \begin{array}{c}
\text { anybody } \\
\text { wCI }
\end{array} \text { who-with talk-NEG-PST }
\end{aligned}
$$

I argue that wh-phrases are scope-takers and are subject to Scope Rigidity. This explains the ban on covert wh-scrambling, which in turn explains why the intervention effect is present.

But what is the intervention effect exactly? It is easy to see that under a scopal account of wh-phrases, there is no interpretable logical form for (17a), respecting Scope Rigidity. Assuming that the negative concord item has to be in the scope of negation ${ }^{9}$, there are two logical forms that comply with the hierarchies permitted by Scope Rigidity. The LF in (18) is a non-starter, the wh-phrase remains in-situ, causing a type mismatch. In the LF in (19), on the other hand, $\mathrm{QP}_{1}$, which I assume to be an existential quantifier over individuals, cannot combine with its sister, a function from individuals to proposition sets. Notably, even if it could, its licensor,

9 I follow Kelepir (2001) in assuming that negation is an abstract null operator while the negation suffix on the verb simply signals its presence in the clausal spine. 
Demirok

i.e. negation, could not combine with its sister. ${ }^{10}$

(18)

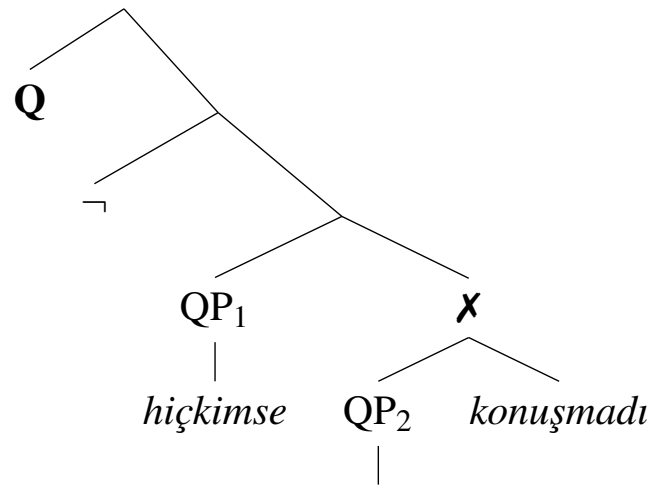

kim-le

(19)

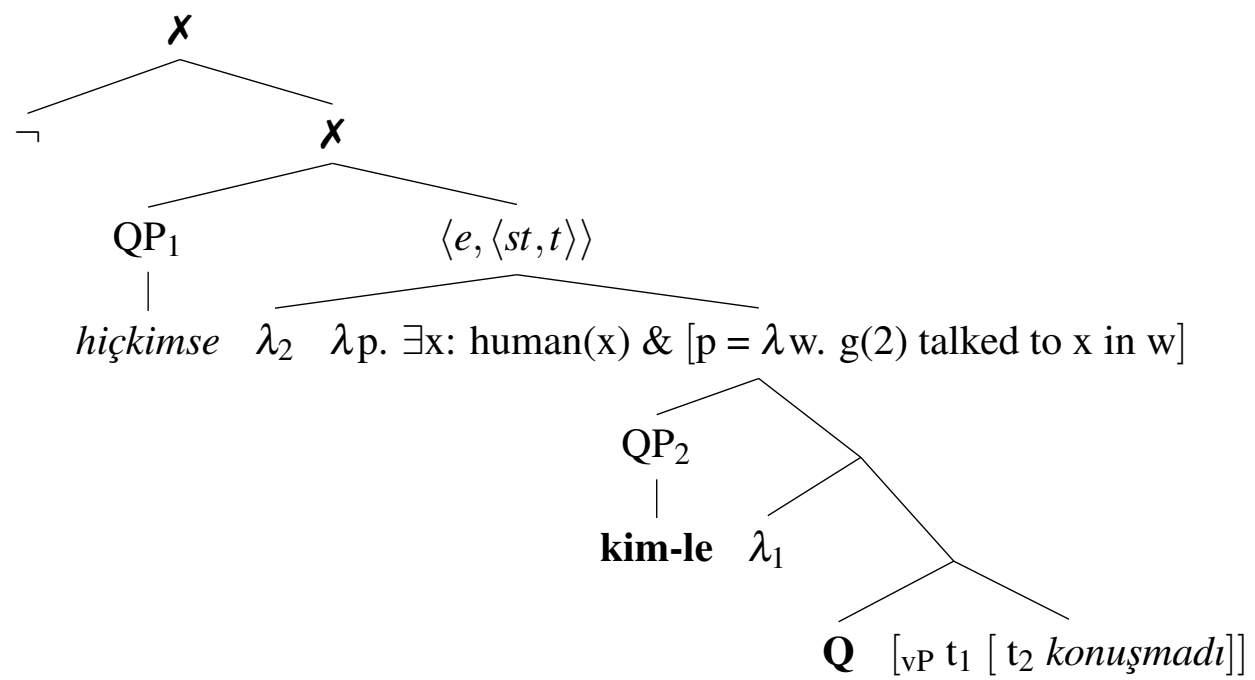

By contrast, the grammatical wh-question in (17b) where $\mathrm{QP}_{2}$ is to the left of $\mathrm{QP}_{1}$ can have the interpretable logical form in (20), where $\mathrm{QP}_{2} \mathrm{c}$-commands $\mathrm{QP}_{1}$.

10 In alternative derivations where wh-phrases QR into a type $t$ node (Fox 2012; Dayal 2016; Demirok 2019), it may be possible to generate the functions below (provided that we suspend plausible syntactic restrictions on what can move above the $\mathrm{Q}$ head). But neither are question meanings:

(i) $\lambda$ p. $\neg \exists \mathrm{y} \exists \mathrm{x}: \operatorname{human}(\mathrm{y}) \& \operatorname{human}(\mathrm{x}) \&[\mathrm{p}=\lambda \mathrm{w}$. y talked to $\mathrm{x}$ in $\mathrm{w}]$

(ii) $\lambda$ p. $\exists \mathrm{x} \neg \exists \mathrm{y}: \operatorname{human}(\mathrm{y}) \& \operatorname{human}(\mathrm{x}) \&[\mathrm{p}=\lambda \mathrm{w}$. $\mathrm{y}$ talked to $\mathrm{x}$ in $\mathrm{w}]$ 
Intervention effects follow from scope rigidity in Turkish

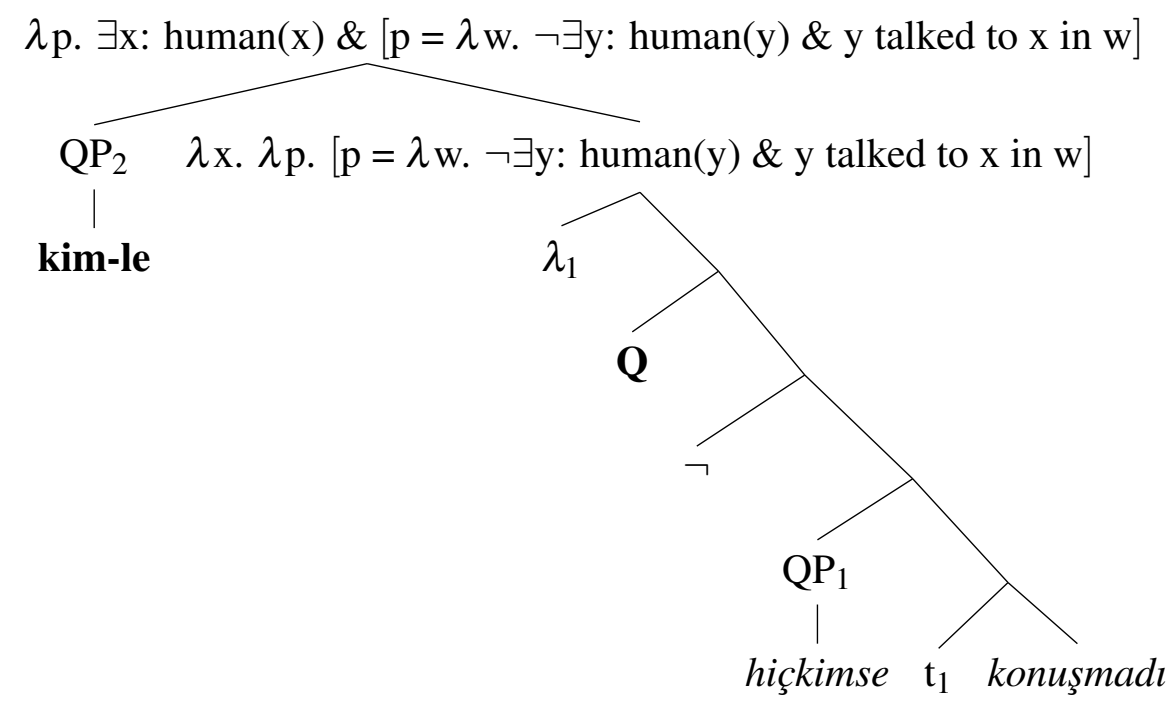

Hence, what allows us to see the so-called intervention effect is Scope Rigidity, namely whatever ensures the fact that a syntactic derivation whose PF output is the string in (17a) cannot have (20) as its LF output. Then, under a scopal account of wh-phrases, Scope Rigidity is all that is needed to explain the ungrammaticality of wh-questions that feature the intervention configuration. Importantly, this is an independently observed constraint in the grammar of Turkish, certainly not a constraint that restates the intervention effect in the form of a syntactic stipulation.

\section{Justifying the proposal}

In the previous section, I have fleshed out my assumptions about Scope Rigidity and the composition of wh-questions, and demonstrated how combining these assumptions correctly predicts intervention effects. In this section, I discuss some further predictions that we make under this proposal. First, I show that intervention is parasitic on rigid interpretation of word order, as predicted under Scope Rigidity. Then, I turn to the evidence for the idea that wh-phrases are scope-takers that are subject to Scope Rigidity. Finally, I discuss what class of expressions are expected to cause intervention in which configurations.

\subsection{Intervention is parasitic on rigid interpretation of word order}

Invoking Scope Rigidity in the explanation of intervention effects finds independent support in configurations where scrambling creates intervention effects. Overtly moving an intervener past a wh-phrase creates intervention in Turkish, as shown in (21b). Given that (21b) lacks an interpretation, we can infer that the intervener in 
(21b) cannot reconstruct to its pre-movement position below the wh-phrase and be interpreted as in (21a). This follows from Scope Rigidity: a derivation that outputs the string in (21b) cannot map to a logical form where $\mathrm{QP}_{1}$ c-commands $\mathrm{QP}_{2}$.

$$
\begin{aligned}
& \text { a. Parti-de }\left[\mathrm{QP}_{1} \text { kim }\right]\left[\mathrm{QP}_{2} \text { hiçkimse-yle }\right] \text { konuş-ma-d1? } \\
& \text { party-LOC who anybody } \mathrm{NCI}^{-} \text {with talk-NEG-PST } \\
& \text { 'Who talked to no one at the party?' } \\
& \text { b. *Parti-de }\left[\mathrm{QP}_{2} \text { hiçkimse-yle }\right] \quad\left[\mathrm{QP}_{1} \text { kim }\right] \mathrm{t}_{\mathrm{QP}_{2}} \text { konuş-ma-d1? } \\
& \text { party-LOC anybody }{ }_{\mathrm{NCI}}-\text { with who talk-NEG-PST }
\end{aligned}
$$

Any account of intervention effects needs to say something about the impossibility of reconstruction here. If one invokes Scope Rigidity to explain the impossibility of reconstruction in examples like (16b) (where a non-wh object quantifier precedes a non-wh subject quantifier), the null hypothesis should be that the same explanation extends to the intervention effect in (21b), and by extension to the intervention effect in sentences like (17a) (where the two QPs appear in the basic subject-object order). Hence, I take intervention created by scrambling to independently suggest Scope Rigidity as the culprit behind intervention effects.

\subsection{Wh-phrases are subject to Scope Rigidity in Turkish}

As we have seen, the fact that Turkish does not allow covert wh-scrambling falls out under the hypothesis that wh-phrases in Turkish are scope-takers that are subject to Scope Rigidity. There is independent evidence for this hypothesis.

A wh-phrase that takes embedded scope cannot precede a matrix clause QP. Consider the baseline sentence in (22) where the wh-phrase, that is the subject of the embedded clause, has embedded scope. When this wh-phrase is scrambled to the left of the matrix clause QP as in (23), it is obligatorily interpreted in its landing position, yielding a matrix wh-question. The inability of the wh-phrase to reconstruct to its pre-movement position strongly suggests that wh-phrases are 'visible' to the calculus of Scope Rigidity. See also Tanaka 2003 for parallel data in Japanese.

$$
\begin{aligned}
& \text { [QP1 Hiçkimse] [ [QP2 kim-in] gittiğini ] bil-m-iyor. } \\
& \text { anybody }_{\mathrm{NCI}} \text { who-GEN leave.NMLZ.3SG know-NEG-IMPF } \\
& \text { 'Nobody knows who left.' } \\
& \text { [QP2 Kim-in] [QP1 hiçkimse] [t } \mathbf{t}_{\mathrm{QP} 2} \text { gittiğini ] bil-m-iyor. } \\
& \text { who-GEN } \text { anybody }_{\mathrm{NCI}} \text { leave.NMLZ.3SG know-NEG-IMPF } \\
& \checkmark \text { 'Who } 1 \text { is such that nobody knows they }{ }_{1} \text { left?' } \\
& \boldsymbol{x} \text { 'Nobody knows who left.' }
\end{aligned}
$$

Furthermore, wh-phrases are also scope rigid with respect to each other. The 
evidence for this comes from cases of split scope. Both the subject and the object of the embedded clause in the sentence in (24) are wh-phrases. The wh-phrases can both have embedded scope, or can both have matrix scope. Split scope is also possible: the subject wh-phrase can have matrix scope while the object wh-phrase has embedded scope. However, the reverse split scope is impossible for the string in (24). In other words, a wh-phrase cannot have matrix scope if it is preceded by an embedded scope wh-phrase. This reading only becomes possible via overt wh-scrambling, as in (25).

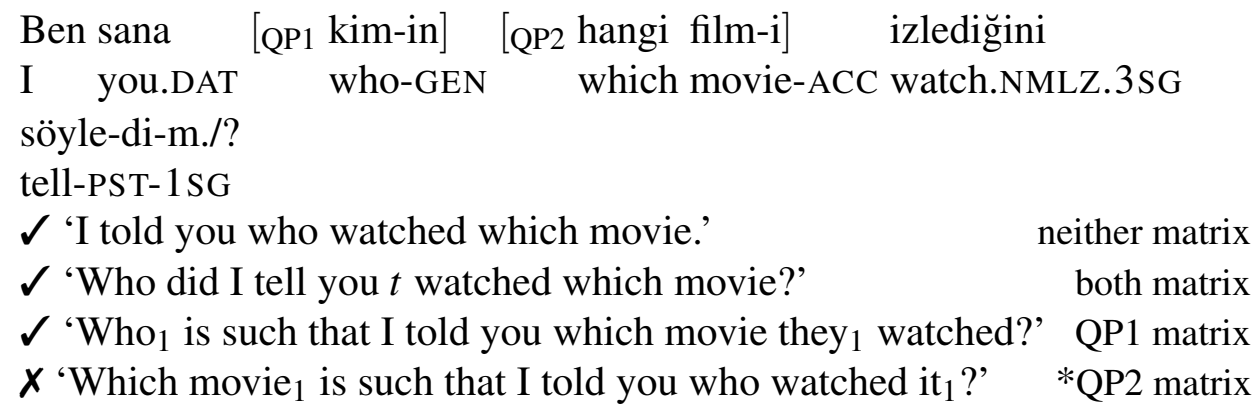

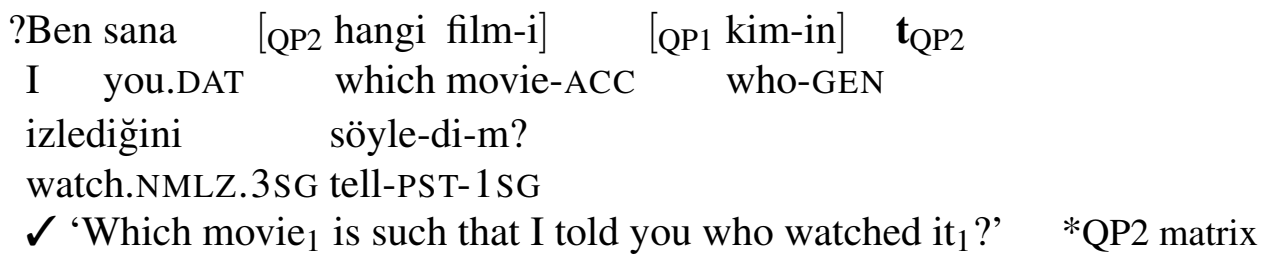

Again, this state of affairs is fully predicted if wh-phrases are scope-takers that are subject to Scope Rigidity. See also Richards 2000 for parallel data in Japanese.

\subsection{What should cause intervention?}

The proposed theory of intervention effects in Turkish makes a clear prediction about the class of interveners. Whatever has to be construed as a scope-taker subject to Scope Rigidity and cannot scope above a wh-phrase will cause intervention.

As we have seen with the negative concord item hiçkimse 'anybody', expressions that have to scope below negation will cause intervention when they precede a wh-phrase. This is because when they precede a wh-phrase, Scope Rigidity forces uninterpretable logical forms where their licensor, i.e. negation, scopes above a whquestion. We can add the NPI herhangi biri 'anybody' and the universal quantifier herkes 'everyone' to the list of quantifiers that need to scope below negation in Turkish (Kelepir 2001). As shown in (26), the prediction is borne out: they cannot precede the wh-phrase. In both cases, intervention is obviated if the object wh-phrase precedes the subject QP, as shown in (27). 

a. * $\left[\mathrm{QP}_{1}\right.$ Herhangi biri $]\left[\mathrm{QP}_{2}\right.$ kimi $]$ sev-m-iyor?

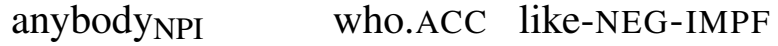
b. $*\left[\mathrm{QP}_{1}\right.$ Herkes $] \quad\left[\mathrm{QP}_{2}\right.$ kimi $]$ sev-m-iyor? everybody who.ACC like-NEG-IMPF
a. $\left[\mathrm{QP}_{2} \mathrm{Kimi}\right] \quad\left[\mathrm{QP}_{1}\right.$ herhangi biri $]$ sev-m-iyor? who.ACC anybodyNPI like-NEG-IMPF
$=\lambda \mathrm{p} . \exists \mathrm{x}: \operatorname{human}(\mathrm{x}) \&\left[\mathrm{p}=\lambda \mathrm{w} . \neg \exists \mathrm{y}: \operatorname{human}(\mathrm{y}) \& \operatorname{like}_{\mathrm{w}}(\mathrm{x})(\mathrm{y})\right]$
b. $\left[\mathrm{QP}_{2}\right.$ Kimi $] \quad\left[\mathrm{QP}_{1}\right.$ herkes $]$ sev-m-iyor? who.ACC everybody like-NEG-IMPF $=\lambda \mathrm{p} . \exists \mathrm{x}: \operatorname{human}(\mathrm{x}) \&\left[\mathrm{p}=\lambda \mathrm{w} . \neg \forall \mathrm{y}: \operatorname{human}(\mathrm{y}) \rightarrow \operatorname{like}_{\mathrm{w}}(\mathrm{x})(\mathrm{y})\right]$

DPs that combine with focus particles sadece 'only', da 'too', and bile 'even' intervene. ${ }^{11}$ Assuming that these can be given scopal treatments (Krifka 1991; Geurts \& van der Sandt 2004; Sauerland 2018), we correctly predict that they have to follow the wh-phrase, for they need to scope inside the question nucleus.
a. * $\left[\mathrm{QP}_{1}\right.$ Sadece Selin $]\left[\mathrm{QP}_{2}\right.$ kim-le $]$ konuştu? only Selin who-with talk.PST
Intended: 'Who is such that only Selin talked to them?'
b. * $\left[\mathrm{QP}_{1}\right.$ Selin de $]\left[\mathrm{QP}_{2}\right.$ kim-le $]$ konuştu? Selin too who-with talk.PST
Intended: 'Who is such that Selin, too, talked to them?'
c. * $\left[\mathrm{QP}_{1}\right.$ Selin bile $]\left[\mathrm{QP}_{2}\right.$ kim-le $]$ konuştu? Selin even who-with talk.PST Intended: 'Who is such that even Selin talked to them?'

There is independent evidence that such expressions are scope-takers and are subject to Scope Rigidity, as shown by the data in (29).
a. $\left[\mathrm{QP}_{1}\right.$ Hiçkimse $] \quad\left[\mathrm{QP}_{2}\right.$ sadece Selin-le $]$ konuş-ma-d1. anybody $_{\mathrm{NCI}}$ only Selin-with talk-NEG-PST
$\checkmark$ 'Nobody is such that Selin is the only one they talked to.' $\boldsymbol{x}$ 'Selin is the only one that nobody talked to.'
b. $\quad\left[\mathrm{QP}_{2}\right.$ Sadece Selin-le $] \quad\left[\mathrm{QP}_{1}\right.$ hiçkimse $]$ konuş-ma-d. only Selin-with anybody $_{\mathrm{NCI}}$ talk-NEG-PST $\checkmark$ 'Selin is the only one that nobody talked to.' $\boldsymbol{x}$ 'Nobody is such that Selin is the only one they talked to.'

11 Howell, Hohaus, Polina Berezovskaya, Braun, Durmaz \& Beck (2021) report that only sadece allows long distance association. Indeed, sadece can associate, from the edge of an island, with a constituent that the island contains. I leave it to future work to flesh out a scopal analysis of this pattern. I refer the reader to Sauerland 2018 and Demirok 2019 to see how such an account might look like. 
Intervention effects follow from scope rigidity in Turkish

This behavior contrasts with the yes-no question particle $m i$ which can attach to DPs, as shown in (30a). Surprisingly, this particle can also appear in wh-questions, forming a yes-no question about the wh-question, as the non-literal translation of (30c) should suggest. ${ }^{12}$ Given this apparent function of $m i$-phrases in wh-questions, it seems that they need to scope above the wh-question. This is verified by the 'reverse intervention' pattern we find below: the $m i$-phrase has to precede the whphrase. This is again fully predicted by Scope Rigidity, if $m i$-phrases in wh-questions scope above the wh-question.
a. Pilav-1 [Pelin mi $]$ bitir-di?
rice-ACC Pelin YNQ finish-PST
'Was it Pelin who finished the rice?'
b. * $\left[\mathrm{QP}_{1} \mathrm{Kim}\right]\left[\mathrm{QP}_{2}\right.$ Selin-le mi $]$ konuş-tu?
who Selin-with YNQ talk-PST
Intended: 'Are you asking me who talked to SELIN?'
c. $\mathrm{QP}_{2}$ Selin-le mi $]\left[\mathrm{QP}_{1}\right.$ kim $]$ konuş-tu?
Selin-with $\mathrm{YNQ}$ who talk-PST
'Are you asking me who talked to SELIN?'

We see a somewhat similar pattern in embedded questions. If a QP that the precedes the wh-phrase can be scoped out of the embedded wh-question (preferably marked by a short pause right after the QP), there is no intervention, as shown by the examples in (31). The absence of intervention in this configuration is again fully predicted under the proposed account. See also Erlewine \& Kotek 2017b; Kotek 2019a for parallel observations in Japanese.
a. Her ögrenci-nin, hangi notu
aldı ̆1
belli.
every student-GEN which grade.ACC get.NMLZ.3SG obvious
$\checkmark$ Each student $\mathrm{x}$ is such that it is obvious which grade $\mathrm{x}$ got.
b. Hiçbirimiz-in, hangi notu aldığı belli değil. any.of.us $\mathrm{NCI}^{-G E N}$ which grade.ACC get.NMLZ.3SG obvious NEG
$\checkmark$ No $x$ among us is such that it is obvious which grade $\mathrm{x}$ got.
c. Sadece Pelin-in, hangi notu aldiğ 1 belli. only Pelin-GEN which grade.ACC get.NMLZ.3SG obvious $\checkmark\{$ Pelin $\}=\{\mathrm{x}$ : it's obvious which grade $\mathrm{x}$ got $\}$.

Finally, the current account predicts that intervention can be escaped when a potential intervener can assume a non-scopal construal. For example, NPs modified by numerals can assume a non-scopal construal (a definite description), as shown in

12 See Kamali \& Krifka 2020 for a thorough discussion of contrastive topics in wh-questions in Turkish, which presents a pattern similar to the one reported here. 
(32a). Similarly, universal quantifiers, under a collective interpretation, can assume a non-scopal construal and escape intervention, as shown in (32b).

a. (O) iki ögrenci hangi soruyu cevapla-dı? (that) two student which question. ACC answer-PST $\approx$ 'Which question is such that those/the two students answered it?'

b. Bütün ögrenciler hangi soruyu cevapla-ma-dı? all students which question. ACC answer-NEG-PST $\checkmark$ 'Which question is such that (all) students didn't answer it?' $\boldsymbol{X}$ 'Which question is such that not all students answered it?'13

While a rigorous testing of a wide range of quantifiers is surely necessary, the empirical survey on intervention effects that Kesen (2010) reports seems to align with the predictions of the account developed here. Quantifiers that need to scope below negation and DPs that are turned into scope-takers by focus particles cause the sharpest intervention effects - getting the lowest acceptability ratings (i.e. around 1/5). While other kinds of quantifiers such as DPs marked by numerals and quantifiers that do not resist a non-scopal construal cause varying levels of degradedness (roughly clustering around 3.5/5), possibly correlating with varying levels of difficulty that speakers might have in coercing different kinds of quantifiers into a non-scopal interpretation. I believe that this hypothesized correlation is on the right track but leave an in-depth investigation into future work.

\section{Final remarks}

Building on the insight in Erlewine \& Kotek 2017b,a and Kotek 2019a, I have argued that intervention effects in wh-questions follow as a direct consequence of Scope Rigidity under a scopal account of wh-phrases.

Although this account simply combines existing proposals, it had not been previously entertained in the literature, to the best of my knowledge. Presumably, it was thought to be a non-starter because wh-in-situ is typically island-insensitive, apparently requiring a non-scopal account for wh-phrases. However, as mentioned in section 3.1, articulated scopal accounts of island-insensitivity are now available (Demirok 2019; Charlow 2020; Elliott 2021). Under these accounts, islands are lifted into scope-takers, allowing us to semantically implement the syntactic mechanism of island pied-piping (Nishigauchi 1990; Özsoy 1996; Richards 2000). Such accounts, combined with Scope Rigidity, should predict that overt island-piping will be observed in intervention configurations (to escape intervention). This prediction

13 This reading is possible if the wh-phrase precedes bütün ögrenciler, as predicted by Scope Rigidity. 
Intervention effects follow from scope rigidity in Turkish

is borne out in Turkish, as shown in (33). ${ }^{14}$ Needless to say, this just sketches how island-insensitivity and intervention effects would play out together under this account. I leave a fully worked out account to a future occasion.

a. *[Sadece Pelin $]_{1}$ [island kim-den gelen hediye-yi $]_{2}$ beğen-di? only Pelin who-ABL come.REL gift-ACC like-PST

b. [island Kim-den gelen hediye-yi $]_{2}[\text { sadece Pelin }]_{1} t_{2}$ beğen-di? who-ABL come.REL gift-ACC only Pelin like-PST $\checkmark{ }^{\prime} \mathrm{Who}_{1}$ is such that only Pelin liked [the gift that came from them 1 ]?'

This short contribution leaves some questions open. The most pressing one is the apparently idiosyncratic specification of QPs for scope rigidity in Japanese. Recall that Erlewine and Kotek identify whether an expression is scope rigid based on its ability to reconstruct under negation. I have shown that this diagnostics does not work for Turkish, failing to predict what will cause intervention. Instead, I have assumed that Scope Rigidity must be a general principle that bans inverse scope (e.g. by constraining the set of licit PF and LF outputs for a given syntactic derivation). It is not yet clear to me how idiosyncratic rigidity specification can be made compatible with a global understanding of Scope Rigidity. ${ }^{15}$ However, it should be noted that if we can make this work and show that reconstruction is possible for a given QP (i.e. it can escape Scope Rigidity), the facts Erlewine and Kotek report for Japanese would also be compatible with the account proposed here. If a scope-taker that precedes a wh-phrase can reconstruct to its base position below the wh-phrase, the current account, too, predicts obviation of intervention.

Finally, there are cases of nested QPs, where one scope-taker appears inside another but has semantic scope above it, as in (34). ${ }^{16}$ In the interpretable logical form for the wh-question in (34), $\mathrm{QP}_{2}$ needs to have moved out of its container, i.e. $\mathrm{QP}_{1}$, and scope above the $\mathrm{Q}$ head.

$$
\begin{aligned}
& \text { Pelin }\left[\mathrm{QP}_{1} \underline{\text { sadece }}\left[\mathrm{QP}_{2} \text { hangi soruyu }\right]\right. \text { cevapla-d1? } \\
& \text { Pelin only which question.ACC answer-PST } \\
& \lambda \text { p. } \exists x \text { : question }(x) \&[p=\lambda w .[\{x\}=\{y: \text { Pelin answered } y \text { in } w\}]]
\end{aligned}
$$

Turkish does not allow such a derivation to be reflected overtly in the PF output, raising questions about what Scope Rigidity would say about such un-nesting derivations in which $\mathrm{QP}_{1}$ starts out as dominating $\mathrm{QP}_{2}$ but $\mathrm{QP}_{2}$ ends up c-commanding $\mathrm{QP}_{1}$. I leave this as a challenge for a comprehensive formalization of Scope Rigidity.

14 Though see Morita 2019 who reports variation on this among wh-in-situ languages. 15 In optimality-theoretic grammars, this is doable. See Bobaljik \& Wurmbrand 2012. 16 See Li \& Law 2014 for parallel data in Mandarin. 
Demirok

\section{References}

Beck, Sigrid. 1996. Quantified structures as barriers for LF movement. Natural Language Semantics 4. 1-56. doi:10.1007/BF00263536.

Beck, Sigrid. 2006. Intervention effects follow from focus interpretation. Natural Language Semantics 14. 1-56. doi:10.1007/s11050-005-4532-y.

Beck, Sigrid \& Shin-Sook Kim. 1997. On wh- and operator scope in Korean. Journal of East Asian Linguistics 339-384. doi:10.1023/A:1008280026102.

Bobaljik, Jonathan David \& Susi Wurmbrand. 2012. Word order and scope: Transparent interfaces and the 3/4 Signature. Linguistic Inquiry 43(3). 371-421. doi:10.1162/LING_a_00094.

Branan, Kenyon. 2018. Relationship Preservation: MIT PhD dissertation.

Cable, Seth. 2010. The Grammar of Q: Q-Particles, Wh-Movement, and Pied-piping. Oxford University Press.

Charlow, Simon. 2014. On the Semantics of Exceptional Scope: NYU PhD dissertation.

Charlow, Simon. 2020. The scope of alternatives: indefiniteness and islands. Linguistics and Philosophy 43. 427-472. doi:10.1007/s10988-019-09278-3.

Chomsky, Noam. 1993. A minimalist program for linguistic theory. In Kenneth Hale \& Samuel Jay Keyser (eds.), The View from Building 20: Essays on Linguistics in Honor of Sylvain Bromberger, 1-52. Cambridge, Mass.: MIT Press.

Dayal, Veneeta. 2016. Questions. Oxford University Press.

Demirok, Ömer. 2019. Scope Theory Revisited: Lessons from Pied-piping in Whquestions: MIT PhD dissertation.

Elliott, Patrick. 2015. Nested wh-questions and the locality of scope-taking. Slides from Questions at the Syntax-Semantics Interface.

Elliott, Patrick. 2021. A flexible scope theory of intensionality. Accepted with minor revisions at Linguistics \& Philosophy.

Elliott, Patrick \& Uli Sauerland. 2019. Nuclear Intervention - Deriving Beckeffects via cyclic scope and local exhaustification. Slides from ExQA2019. https://patrl.keybase.pub/slides/tuebingen-slides.pdf.

Erlewine, Michael Yoshitaka \& Hadas Kotek. 2017a. Intervention tracks scoperigidity in Japanese. Logic and Engineering of Natural Language Semantics (LENLS) 14.

Erlewine, Michael Yoshitaka \& Hadas Kotek. 2017b. Movement and alternatives don't mix: Evidence from Japanese. Amsterdam Colloquium (AC) 21. 245-254.

Fox, Danny. 2012. The Semantics of Questions. Lecure notes, MIT.

Geurts, Bart \& Rob van der Sandt. 2004. Interpreting focus. Theoretical Linguistics 30. 1-44. doi:10.1515/thli.2004.005.

Hagstrom, Paul. 1998. Decomposing Questions: MIT PhD dissertation. 
Intervention effects follow from scope rigidity in Turkish

Hamblin, Charles L. 1973. Questions in Montague English. Foundations of Language 1. 41-53. https://www.jstor.org/stable/25000703.

Heim, Irene. 2000. Notes on interrogative semantics. Lecture notes, MIT.

Heim, Irene. 2018. Functional readings without type-shifted noun phrases. In Manfred Krifka \& Mathias Schenner (eds.), Reconstruction Effects in Relative Clauses, 283-302. Berlin, Boston: De Gruyter.

Heim, Irene \& Angelika Kratzer. 1998. Semantics in Generative Grammar. Oxford: Blackwell.

Hoji, Hajime. 1985. Logical Form Constraints and Configurational Structures in Japanese: University of Washington PhD dissertation.

Howell, Anna, Vera Hohaus, Konstantin Sachs Polina Berezovskaya, Julia Braun, Şehriban Durmaz \& Sigrid Beck. 2021. (No) variation in the grammar of alternatives. In Linguistic Variation: Online-First Articles, John Benjamins. doi:10.1075/1v.19010.how.

Kamali, Beste \& Manfred Krifka. 2020. Focus and contrastive topic in questions and answers, with particular reference to Turkish. Theoretical Linguistics 46(1-2). 1-71. doi:10.1515/tl-2020-0001.

Karttunen, Lauri. 1977. Syntax and semantics of questions. Linguistics \& Philosophy 1. 3-44. https://www.jstor.org/stable/25000027.

Kelepir, Meltem. 2001. Topics in Turkish Syntax: Clausal Structure and Scope: MIT $\mathrm{PhD}$ dissertation.

Kesen, Yasemin. 2010. Intervention Effects in Simple Wh-questions in Turkish: Boğaziçi University MA thesis.

Kotek, Hadas. 2019a. Wh-intervention is caused by movement into regions of focus alternatives computation. Ms, Yale University.

Kotek, Hadas. 2019b. Composing Questions. The MIT Press.

Kratzer, Angelika \& Junko Shimoyama. 2002. Indeterminate pronouns: The view from Japanese. The Tokyo Conference on Psycholinguistics (TCP) 3. 1-25.

Krifka, Manfred. 1991. A compositional semantics for multiple focus constructions. Semantics and Linguistic Theory (SALT) 1. 127-158. doi:10.3765/salt.v1i0.2492.

Li, Haoze \& Jess Law. 2014. Focus intervention: A quantificational domain approach. North East Linguistics Society (NELS) 44. 273-287.

Mayr, Clemens. 2014. Intervention effects and additivity. Journal of Semantics 31. 513-554. doi:10.1093/jos/fft010.

Mayr, Clemens. 2020. Intervention effects. In Daniel Gutzmann, Lisa Matthewson, Cécile Meier, Hotze Rullmann \& Thomas Zimmermann (eds.), The Wiley Blackwell Companion to Semantics, John Wiley \& Sons. doi:10.1002/9781118788516.sem069.

Morita, Hisashi. 2019. Intervention effects inside islands in wh-in-situ languages. Handout from Workshop on Approaches to Wh-Intervention. 
https://lingconf.com/intervention/wp-content/uploads/sites/11/2019/06/morita. pdf.

Nishigauchi, Taisuke. 1990. Quantification in the Theory of Grammar. Kluwer, Dordrecht.

Novel, Marc \& Maribel Romero. 2010. Movement, variables and Hamblin alternatives. Sinn und Bedeutung (SuB) 14. 322-338.

Özsoy, A. Sumru. 1996. A'-dependencies in Turkish. Current Issues in Turkish Linguistics 5. 139-158.

Öztürk, Balk1z. 2005. Case, Referentiality and Phrase Structure. Philadelphia, PA: John Benjamins.

Özyıld1z, Deniz. 2017. Quantifiers in Turkish. In Denis Paperno \& Edward Keenan (eds.), Handbook of Quantifiers in Natural Language: Volume II, doi:10.1007/978-3-319-44330-0_17.

Partee, Barbara H. 1986. Noun phrase interpretation and type-shifting principles. In Jeroen Groenendijk, Dick de Jongh \& Martin Stokhof (eds.), Studies in Discourse Representation Theory and the Theory of Generalized Quantifiers, 115-143. Dordrecht: Foris.

Percus, Orin. 2000. Constraints on some other variables in syntax. Natural Language Semantics 8. 173-229. doi:10.1023/A:1011298526791.

Pesetsky, David. 2000. Phrasal Movement and its Kin. MIT Press.

Reinhart, Tanya. 1998. Wh-in-situ in the framework of the Minimalist Program. Natural Language Semantics 6(1). 29-56. http://www.jstor.org/stable/23748255.

Richards, Norvin. 2000. An island effect in Japanese. Journal of East Asian Linguistics 9. 187-205. https://www.jstor.org/stable/i20100778.

Rooth, Mats. 1985. Association with Focus: University of Massachusetts PhD dissertation.

Sauerland, Uli. 2018. Alternative generation and cyclic scope. Handout from a talk at Diderot University, Paris, November 28.

Shan, Chung-chieh. 2004. Binding alongside Hamblin alternatives calls for variable-free semantics. Semantics and Linguistic Theory (SALT) 14. 289-304. doi:10.3765/salt.v14i0.2901.

Shibata, Yoshiyuki. 2015. Exploring Syntax from the Interfaces: University of Connecticut $\mathrm{PhD}$ dissertation.

Shimoyama, Junko. 2006. Indeterminate phrase quantification in Japanese. Natural Language Semantics 14(2). 139-173. doi:10.1007/s11050-006-0001-5.

Tanaka, Hidekazu. 2003. Remarks on Beck's effects: Linearity in syntax. Linguistic Inquiry 34. 314-323. doi:10.1162/ling.2003.34.2.314. 
Intervention effects follow from scope rigidity in Turkish

Ömer Demirok

Department of Linguistics

Boğaziçi University

Bebek 34342, İstanbul - TURKEY

omerfaruk.demirok@boun.edu.tr 